\title{
Diet breadth and exploitation of exotic plants shift the core microbiome of Cephaloleia, a group of tropical herbivorous beetles
}

\author{
Chelsea L. Blankenchip $^{1}{ }^{\text {, Dana E. Michels }}{ }^{1}$, H. Elizabeth Braker ${ }^{1}$, Shana K. Goffredi ${ }^{\text {Corresp. } 1}$ \\ 1 Department of Biology, Occidental College, Los Angeles, CA, United States \\ Corresponding Author: Shana K. Goffredi \\ Email address: sgoffredi@oxy.edu
}

The beetle genus Cephaloleia has evolved in association with tropical ginger plants and for many species their specific host plant associations are known. Here we show that the core microbiome of six closely-related Costa Rican Cephaloleia species comprises only 8 bacterial groups, including members of the Acinetobacter, Enterobacteriacea, Pseudomonas, Lactococcus, and Comamonas. The Acinetobacter and Enterobacteriacea together accounted for $35 \%$ of the total average $16 \mathrm{~S}$ rRNA ribotypes recovered from all specimens. Further, microbiome diversity and community structure was significantly linked to beetle diet breadth, between those foraging on $<2$ plant types (specialists) versus $9+$ plants (generalists). Moraxellaceae, Enterobacteriaceae, and Pseudomonadaceae were highly prevalent in specialist species, and also present in eggs, while Rickettsiaceae associated exclusively with generalist beetles. Bacteria isolated from Cephaloleia digestive systems had distinct capabilities and suggested a possible beneficial role in both digestion of plant-based compounds, including xylose, mannitol, and pectin, and possible detoxification, via lipases. Cephaloleia species are currently expanding their diets to include exotic invasive plants, yet it is unknown whether their microbial community plays a role in this transition. In this study, colonization of invasive plants was correlated with a dysbiosis of the microbiome, suggesting a possible relationship between gut bacteria and niche adaptation. 
1

2

3

4

5

6

7

8

9

10

11

12

13

14

15

16

17

18

19

20

21

22

23

$24 *$ Corresponding Author:

25

26 Dr. Shana K. Goffredi

27 Biology Dept.

28 Occidental College

291600 Campus Rd

30 Los Angeles, CA 90041

31 sgoffredi@oxy.edu

32 323-259-1470 
33 The beetle genus Cephaloleia has evolved in association with tropical ginger plants and for many species 34 their specific host plant associations are known. Here we show that the core microbiome of six closely35 related Costa Rican Cephaloleia species comprises only 8 bacterial groups, including members of the 36 Acinetobacter, Enterobacteriacea, Pseudomonas, Lactococcus, and Comamonas. The Acinetobacter and 37 Enterobacteriacea together accounted for $35 \%$ of the total average 16S rRNA ribotypes recovered from all 38 specimens. Further, microbiome diversity and community structure was significantly linked to beetle diet breadth, between those foraging on $<2$ plant types (specialists) versus 9+ plants (generalists). Moraxellaceae, Enterobacteriaceae, and Pseudomonadaceae were highly prevalent in specialist species, and also present in eggs, while Rickettsiaceae associated exclusively with generalist beetles. Bacteria isolated from Cephaloleia digestive systems had distinct capabilities and suggested a possible role in both digestion of plant-based compounds, including xylose, mannitol, and pectin, and detoxification, via lipases. Cephaloleia species are currently expanding their diets to include exotic invasive plants, yet it is unknown whether their microbial community plays a role in this transition. In this study, colonization of invasive plants was correlated with a dysbiosis of the microbiome, suggesting a possible relationship between gut bacteria and niche adaptation. 


\section{INTRODUCTION}

Mutually beneficial symbioses are the rule, rather than the exception, and the discovery and elucidation of the role of symbiotic microorganisms to animal life has emerged as an important area of research. Among insects, persistent bacterial partnerships are well documented and believed to play a critical role in host adaptation to specific niches. Microbiological studies on aphids, stinkbugs, psyllids, white flies, mealybugs, and leaf-hoppers have provided insights into the physiological, ecological, and evolutionary history of bacterial symbioses with insects that primarily consume plant sap (reviewed in 1-4). It is widely accepted that symbioses allow insect herbivores to exploit plants more effectively, however little specific evidence has been reported for chewing phytophagous insects, particularly in the understudied tropical rainforests (5-7).

With more than 200 described species, the neotropical beetle genus Cephaloleia (Chevrolat) has evolved in specific association with gingers in the order Zingiberales (8-11). For $\sim 50 \mathrm{MY}$, Cephaloleia beetles have specialized on the immature rolled leaves of these gingers, which they use for nutrition, development, reproduction, and as shelter (12). Unlike most tropical insects, host plant associations are known for most of the sympatric species of Cephaloleia that inhabit the lowland rainforest in and around La Selva Biological Station, Costa Rica (13-14). As a group, they display variability in diet breadth, ranging from hypergeneralist species, such as Cephaloleia belti (Baly, 1885) which feeds on 15+ plants from three Zingiberales families, to specialist species, such as Cephaloleia placida (Baly, 1885) which is only found on a single plant species $(12,15)$. Studies exploring the link between gut bacterial community and diet in non-sap sucking insects have produced conflicting results (16-18), and very few have examined closely-related insects with both generalist and specialist feeding strategies. Fierer and colleagues recommended that in order to resolve the effects of diet on the microbiome, future studies should focus on a single group of insects with varied diets (17). Thus, the contrasting dietary breadths of Cephaloleia beetles make them an ideal natural group by which to examine the, perhaps reciprocal, role of the microbiome on niche adaptation. Additionally, in the last two decades, at least four Zingiberales from South America have invaded the tropical rainforest of La Selva, including the pink velvet banana and white ginger lily (19). Interestingly, at least eight Cephaloleia beetle species, including several specialists, are currently expanding their diets to exploit these novel Zingiberales (19).

Understanding the presence, diversity, and pervasiveness of bacteria associated with insects, especially in relation to diet breadth, is a necessary and integral component of insect nutritional ecology (20). In this paper, we sought to characterize the diversity of bacteria, via 16S rRNA sequencing and bacterial cultivation, associated with adults (and a small number of eggs) of six species of Cephaloleia beetles, including two generalist and four specialist species. Initially we hypothesized that generalist species would have a more diverse microbiome, as an adaptation to a wide range of plant types or as a consequence of increased encounters with diverse bacteria associated with plant tissues (7,21). Major beetle bacterial groups were cultured to determine their metabolic capabilities and whether they might aid in plant digestion or detoxification of plant compounds by the host insect. Three Cephaloleia species were collected from invasive white ginger and pink banana, including the generalist $C$. belti and specialists $C$. placida and Cephaloleia dilaticollis (Baly, 1858). Comparisons between beetles feeding on native versus invasive plants was expected to reveal specific bacterial groups related to colonization of exotic plants and provide a better understanding of the role of the microbiome in adaptation. 
91

92

93

94

95

96

97

98

99

100

101

102

103

104

105

106

107

108

109

110

111

112

113

114

115

116

117

118

119

120

121

122

123

124

125

126

127

128

129

130

131

132

133

134

\section{MATERIALS AND METHODS}

Specimen Collection. Adult beetles ( $\mathrm{n}=38$; Figure 1) were collected in 2014-2016 at La Selva Biological Station, a 1500-hectare ecological reserve in a lowland tropical rainforest site in northern Costa Rica $\left(10^{\circ} 26^{\prime} \mathrm{N}, 83^{\circ} 59^{\prime} \mathrm{W}\right.$; current Costa Rican Ministry of the Environment and Energy permit \#R-026-2015OT-CONAGEBIO). Adults were located by searching for rolled Zingiberales leaves that were then unrolled and beetles collected with forceps. Beetles with excised exoskeletons were preserved in $70 \%$ ethanol, at $4^{\circ} \mathrm{C}$, for later molecular analysis. Cephaloleia eggs $(n=5)$ were collected adhered to plastic after mating pairs were kept for a brief time in captivity in bags. Usually the adults laid eggs on the plastic, which was remote from where they spent most of their time (in a rolled leaf near the bottom of the bag, or in the zipper seals of the bag). The piece of plastic with attached egg was then surface sterilized and kept in ethanol until analysis. Any bacterial presence in the eggs was therefore attributed to vertical transmission by adults, and not due to adult contamination of the eggs. For bacterial cultivation, the digestive systems of the beetles were dissected in sterile $1 \mathrm{X}$ phosphate buffered saline (PBS) and homogenized using a ground glass mortar and pestle. The resulting homogenate was spread onto Trypticase Soy Agar (TSA) and incubated at ambient temperatures. Resulting bacterial colonies were selected and stored at $-80^{\circ} \mathrm{C}$ in $30 \%$ glycerol (in $1 \mathrm{X}$ PBS). All samples were transported back to the US for further processing.

Specimen Identification. Adult beetles were identified based on diagnostic morphology and host plant (the latter mainly for specialist beetles that feed on only a single plant type; 12,15). In one cased we employed DNA analysis for identification; Cephaloleia dilaticollis currently encompasses two cryptic species, one of which is a specialist and the other a generalist. Total genomic DNA was extracted using the Qiagen DNeasy Kit (Qiagen, Valencia, CA) according to the manufacturer's instructions. The cytochrome c oxidase I (COI) gene was amplified via the polymerase chain reaction (PCR) using the insect COI primers 1718F (5'-GGAGGATTTGGAAATTGATTAGTTCC-3') and 3661R (5'CCACAAATTTCTGAACATTGACCA-3') according to McKenna and Farrell 2005 (12). Successful PCR reactions, determined via electrophoresis, were cleaned using MultiScreen HTS plates (Millipore Corporation, Bedford, MA) and sequenced via Laragen, Inc. (Los Angeles, CA). Beetle species identification was confirmed based on COI sequences, upon consultation with Dr. Carlos García-Robledo (University of Connecticut).

Molecular Microbiome Analysis. Adult Cephaloleia beetles from 6 species found on native plants $(\mathrm{n}=$ $29)$ and 3 species found on invasive plants $(n=9)$ were examined for microbiome composition via $16 \mathrm{~S}$ rRNA gene barcode sequencing (Table 1). As described above, total genomic DNA was extracted using the Qiagen DNeasy Kit (Qiagen, Valencia, CA) according the manufacturer's instructions. All extractions were from individual beetles, with the exception of Cephaloleia dorsalis (Baly, 1885) which due to its small size, 2-3 individuals were pooled to achieve positive PCR results. PCR amplification of the bacterial 16S rRNA gene was performed using the specific primers, 515F (5'-GTGCCAG-

CMGCCGCGGTAA-3') and 806R (5'-GGACTACHVGGGTWTCTAAT-3'; 22). The thermal cycling profile used was as follows: an initial denaturation at $94^{\circ} \mathrm{C}$, then $45 \mathrm{sec}$ at $94^{\circ} \mathrm{C}, 1$ minute at $50^{\circ} \mathrm{C}$, and $90 \mathrm{sec}$ at $72^{\circ} \mathrm{C}$, for 29 cycles, followed by 10 minutes at $72^{\circ} \mathrm{C}$. Successful PCR amplifications, assessed via electrophoresis, were pooled, in duplicate, and barcodes were added according to the Earth 
135 Microbiome Project (EMP; 22); $5 \mu 1$ of the amplicon product from PCR\#1 was used as template in a

1365 cycle, $25 \mu 1$ reconditioning reaction with the same EMP-recommended conditions and the full EMP

137 primers (515f_barcode: AATGATACGGCGAC-CACCGAGATC-

138 TACACTATGGTAATTGTGTGCCAGCMGCCGCGGTAA; 806r_barcode: CAAGCAGAA-

139 GACGGCATACGAGAT-X-AGTCAGTCAGCCGGACTACHVGGGTWTCTAAT), where X

140 indicates a unique 12-bp barcode. Adding the barcode indices at the second step minimizes PCR bias

141 that would result from employing long primers over many cycles (23). Further, the use of the

142 'reconditioning' PCR for barcoding, as well as the pooling of duplicate amplifications ahead of barcoding,

143 was an attempt to minimize PCR errors and bias, respectively (24). Samples were mixed together in

144 equimolar amounts and purified in bulk through a Qiagen PCR Purification kit. At all PCR steps,

145 amplification success and purity was checked by gel electrophoresis. Paired-end sequences

146 (2x 250 basepair) were generated from barcoded amplicon products at Laragen, Inc on an Illumina

147 MiSeq platform. At Laragen, the raw data was passed through a filter which demultiplexed the library

148 into individual samples and removed any sequences which had $>1$ basepair mismatch on the 12-

149 basepair barcode sequence, and assigned quality scores to each basepair call on every sequence. At the

150 same time, adapter, barcode, and primer sequences were removed.

151

152

153

154

155

156

157

158

159

Sequence processing was performed in QIIME 1.8.0 (Quantitative Insights Into Microbial Ecology; 25). Sequences were clustered at $99 \%$ similarity and a representative sequence from each cluster was assigned a taxonomic identification using parameter $-\mathrm{m}$ in QIIME and the Silva115 database. Via barcode amplicon sequencing, 13829 to 68837 sequences were recovered from each specimen (Table 1, Supplemental Table S1). To avoid artifacts of sequencing depth, the number of sequence reads was standardized to 13829 sequences per specimen, based on the lowest sequence number for specimen 'Cp_inv1' (C. placida on invasive white ginger; Table 1). The dataset was further cut off at $1 \%$ (i.e. the number of sequence hits for a single bacterial OTU across all 38 specimens must have been greater than 138 to be included). After this cutoff, sequences ranged from 9899-13324 per specimen (Table 1). Wolbachia was observed in 18 specimens, among 3 species (range of 0.1-56.6\% for all sequences; $C$. belti avg $22 \pm 18 \%$, C reventazonica avg $41 \pm 17 \%$, C. fenestrata avg $10 \pm 13 \%$,), but was removed from subsequent analysis based on its known prevalence in insects as a reproductive pathogen (Supplemental Table S2). Sequences corresponding to chloroplasts and mitochondria were also removed from the data set. NMDS, ANOSIM, and SIMPER analyses were completed in Primer-E after square-root transforming the dataset and calculating Bray-Curtis similarities (26). An ANOSIM R value close to "1.0" suggests dissimilarity between groups. Close environmental and cultured relatives were chosen using top hits based on BLAST (www.ncbi.nlm.nih.gov). RStudio was used to perform ANOVA calculations using a script available at https://sites.oxy.edu/sgoffredi/Symbiosis_Lab/LabScripts.html.

Cephaloleia belti phenotypes and diagnostic PCR. Cephaloleia belti individuals $(n=45)$ were photographed and sized (length and width at pronotum) using imageJ (27). The eight largest and eight smallest beetles were dissected for molecular analysis according to the methods described above. Total DNA of the body of the beetles was extracted using the Qiagen DNeasy Kit (Qiagen, Valencia, CA) according the manufacturer's instructions. For these 16 beetles, a diagnostic PCR using two different sets of pathogen-specific PCR primers was performed specifically for the bacterial genera Rickettsia (Rsp-F 5'- CGCAACCCTCATTCTTATTTGC-3', Rsp-R 5'-CCTCTGTAAACACCAT-TGTAGCA-3'; 28) and Spiroplasma (Spiro_16SF 5'-GGTCTTCGGATTGTAAAGGTCTG-3', Spiro_16SR 5'-

GGTGTGTACAAGACCCGAGAA-3'; 29) with the following thermal protocol: an initial 5 minute denaturation at $94^{\circ} \mathrm{C}$, then 1 minute at $94^{\circ} \mathrm{C}, 1$ minute at $56^{\circ} \mathrm{C}$, and 1 minute at $72^{\circ} \mathrm{C}$, for 29 cycles, and a 
180 final 5 minute extension at $72^{\circ} \mathrm{C}$. Successful PCR amplification was determined via electrophoresis and confirmed to be Rickettsia or Spiroplasma via direct Sanger sequencing (Laragen, Inc).

182

183

184

185

186

187

188

189

190

191

192

193

194

195

196

197

198

199

200

201

202

203

204

205

206

207

208

209

210

211

212

213

214

215

216

217

218

219

220

Bacterial cultivation. Initial bacterial suspensions in 30\% glycerol stocks were re-grown on TSA plates at $30^{\circ} \mathrm{C}$. Growth was checked for morphological purity before being suspended in $40 \mu 1$ of alkaline PEG ( $60 \mathrm{~g}$ of PEG 200 with $0.93 \mathrm{~mL}$ of $2 \mathrm{M} \mathrm{KOH}$ and $39 \mathrm{~mL}$ of water). This suspension was then heated to $96^{\circ} \mathrm{C}$ for 20 minutes in order to lyse the bacterial cells and liberate the DNA. The 16S rRNA gene was then amplified directly using the general PCR primers $27 \mathrm{~F}$ and $1492 \mathrm{R}(30)$ and the following thermal protocol: an initial 5 minute denaturation at $94^{\circ} \mathrm{C}$, followed by $94^{\circ} \mathrm{C}$ for 45 seconds, $54^{\circ} \mathrm{C}$ for 1 minute, and $72^{\circ} \mathrm{C}$ for 90 seconds, for 29 cycles, and a final $72^{\circ} \mathrm{C}$ extension for 10 minutes. Successful amplification were checked via electrophoresis, cleaned using MultiScreen HTS plates (Millipore Corporation, Bedford, MA), and sequenced at Laragen Inc. Sequences were compared with the NCBI BLAST database to determine bacterial identity. Bacteria were propagated on TSA plates to ensure proper activity prior to metabolic testing. The ability to digest lactose/glucose, xylose, mannitol, and pectin was determined using phenol red agar (HiMedia, with $10 \%$ of each substrate). Protein digestion was determined using Litmus Milk tubes purchased from Carolina Biological Supply Company (Burlington, NC USA). The ability to breakdown lipids was tested using an APIZYM analysis (bioMerieux, Inc; Durham, NC USA), according to the manufacturer's instructions.

Data availability. The raw barcode sequence data are available from the Dryad Digital Repository: doi:10.5061/dryad.5fj6t. Raw sequences were aligned and quality control for unidentified base pairs and chimeras was performed according to the specifics noted at https://sites.oxy.edu/sgoffredi/Symbiosis_Lab/LabScripts.html. The QIIME processed data are also available from the Dryad Digital Repository: doi:10.5061/dryad.5fj6t. 16S rRNA sequences for bacterial isolates are available from GenBank under accession numbers MF776885-MF776899.

\section{RESULTS}

The limited core microbiome of Cephaloleia beetles. Using barcode 16S rRNA analysis, the microbiome of adults of six species of Cephaloleia, foraging on native plant diets, was characterized taxonomically (Table 1). Collectively, 168 bacterial OTU's ('operational taxonomic unit'; defined as $99 \%$ sequence similarity) were recovered from all adult specimens examined $(n=29)$, while individual beetles generally associated with $47-152$ OTUs ( $100 \pm 31)$. Greater than $60 \%$ of Cephaloleia specimens contained a core group of eight bacterial OTUs, including three members of the Acinetobacter, two undefined Enterobacteriacea, Pseudomonas, Lactococcus, and a Comamonas (Figures 2-3, Supplemental Table S1). These 8 bacterial OTUs comprised the majority of $16 \mathrm{~S}$ rRNA sequences recovered from each Cephaloleia individual (up to $88 \%$ ).

A single bacterial family, Moraxellaceae dominated the microbiomes of all 29 specimens feeding on native plants, combined (representing $24 \%$ of the total recovered sequences). The genus Acinetobacter, in particular, comprised the vast majority of the Moraxellaceae sequences and accounted for $23 \%$ of the $16 \mathrm{~S}$ rRNA sequences recovered overall. Of the 19 different Acinetobacter OTUs, three were responsible for $60 \%$ of the total Acinetobacter diversity and were each present in $>75 \%$ of beetles (OTUs-131476, 21817 , and 28305; Figure 3, shown in purple; Supplemental Table S1), suggesting them to be members of the 
221

222

223

224

225

226

227

228

229

230

231

232

233

234

235

236

237

238

239

240

241

242

243

244

245

246

247

248

249

250

251

252

253

254

255

256

257

258

259

260

261

core Cephaloleia microbiome. Acinetobacter OTU131476 was found in 22 of 29 specimens, and was $11 \%$ abundant (on average, for all sequences recovered in each of 29 beetles found on native plants; Figure 3). This OTU was $98 \%$ similar to bacteria associated with both leaf cutter ants and fig wasps (GenBank accession \#'s LN564930, HQ639556). Acinetobacter OTU21817 was also found in 22 of 29 specimens, represented 6\% average abundance (Figure 3), and was 100\% similar to bacteria found in the midgut of a leafworm moth (GenBank accession \# KU841476). Acinetobacter OTU28305 was found within 23 of 29 specimens, totalling $6 \%$ average abundance (Figure 3), and was $100 \%$ identical to Acinetobacter baylyi (GenBank accession \# NR115042), and others found in the rhizosphere.

Unidentified Enterobacteriaceae were also dominant in beetles found on native plants, representing 12\% of the total recovered sequences. Of the 10 OTUs that comprised the Enterobacteriaceae within Cephaloleia beetles, a single OTU was responsible for $65 \%$ of the total Enterobacteriaceae diversity. This dominant Enterobacteriaceae OTU-79811 was present in $>93 \%$ of beetle specimens, was $8 \%$ abundant on average (for all 29 beetles found on native plants; Figure 3, shown in blue), and was 100\% similar to Enterobacter/Klebsiella bacteria recovered from scarab beetles, sand flies, and pill bugs (GenBank, unpublished). Two additional OTUs (OTU127346 and OTU79806) each accounted for $\sim 15 \%$ of the remaining Enterobacteriaceae and were present in $>15$ of 29 specimens (Figure 3). These OTUs were related to Citrobacter and Raoultella OTUs found in the microbiome of numerous insects, including honeybees (KR269812), scarab beetles (KT956239) and fruit flies (KX997073).

Three additional OTUs were highly prevalent in Cephaloleia microbiomes (present in $\sim 64 \%$ of individual beetles), including a Lactococcus OTU-157643 representing an average abundance of $\sim 4 \%$ (Figure 3), a Pseudomonas OTU-126400 with an average abundance of $\sim 2 \%$ (related to bacteria recovered from mosquitoes and sand flies; KY041526; 31), and a Comamonas OTU-104860, also with an average abundance of $\sim 2 \%$ (most closely related to bacteria found in association with fruit flies; KX994588; Figure 3, Supplemental Table S1).

A large number of cultured isolates recovered from the digestive systems of Cephaloleia $(81 \%$ of 37 isolated bacterial colonies) were members of the Moraxellaceae, Enterobacteriaceae, and Pseudomonadaceae, based on 16S rRNA gene sequencing. Several isolates had 16S rRNA sequences identical to the dominant bacteria identified via barcode 16S rRNA sequencing, including Acineto3 (= Acinetobacter OTU-28305), Entero4 (= Enterobacteriaceae OTU-127346), and Pseudo2 (= Pseudomonas OTU-126400). The Enterobacteriaceae were found to utilize plant-based compounds, including xylose and pectin ( 7 of 9 isolates), mannitol (8 isolates), and lactose/glucose (all 9 isolates). In contrast, none of the four Acinetobacter isolates in this study were able to digest these compounds, but instead uniquely displayed esterase C4, lipase C8, and lipase C14 capabilities (Figure 4).

Diet breadth influences the microbiome of Cephaloleia beetles. Overall, the microbiome of specialist beetle species was significantly higher in diversity than generalists $(2.6 \pm 0.5$ versus $1.9 \pm 0.5$, respectively; $p=0.0006$, one-way ANOVA, Figure 5). Measures of bacterial diversity (via the Shannon diversity index) were 0.8-2.5 for $C$. belti, 1.1-1.9 for C. reventazonica, 2.1-3.3 C. fenestrata, 2.0-3.0 for $C$. dorsalis, 2.4-2.9 for C. dilaticollis, and 1.5-3.0 for C. placida (Table 1). Further, NMDS ordination revealed the microbial assemblages of Cephaloleia to be strongly differentiated by diet breadth (i.e., generalist versus specialist; $\mathrm{R}=0.74, \mathrm{p}=0.001$, analysis of similarity [ANOSIM]; Figure 6A). SIMPER analysis implicated several bacterial families associated with this difference. For example, the 
262 Moraxellaceae, Enterobacteriaceae, and Pseudomonadaceae comprised a significantly higher percentage

263 of the bacterial community in beetle species categorized as specialists $(34 \%, 17 \%$, and $6 \%$ of recovered

264 sequences on average for specialist individuals, respectively) versus generalists (4\%, 3\%, 0.3\%

265 respectively; all $\mathrm{p}<0.0013$, one-way ANOVA; Figures 2, 5). In contrast, results indicate that generalist

266 Cephaloleia beetles were colonized by bacteria traditionally thought of as pathogens, including Rickettsia

267 and Rickettsiella (discussed in more detail in supplemental results). The Rickettsiaceae comprised a

268 significantly higher percentage of the bacterial community in beetle species categorized as generalists, $C$.

269 belti and C. reventazonica ( $28 \%$ of recovered sequences on average) versus specialists (only $0.8 \% ; \mathrm{p}<$

270 0.0001, one-way ANOVA; Figure 4; Supplemental Table S1). For example, two Rickettsia OTUs

271 (OTU7980 and OTU153335; Rickettsiaceae) were collectively present in only 11 out of 29 specimens,

272 but comprised 11-26\% abundance on average (for all 29 beetles found on native plants; Figure 3). These

273 OTU's were 99\% similar to Rickettsia found in leafhoppers (KR709154) and ticks (MF002591), to name

274 a few. Similarly, a Spiroplasma OTU (Spiroplasmataceae) was present in 12 of 29 specimens,

275 represented an average abundance of $\sim 12 \%$, and was primarily observed in four individuals, two $C$.

276 dorsalis and two C. belti (Figures 2,3). This OTU57080 was 100\% similar to the Spiroplasma associated

277 with Drosophila. The incidence of Rickettsia and Spiroplasma was determined, via diagnostic PCR, to be

278 highest in the smallest individuals of $C$. belti $(81 \%$ prevalence, $\mathrm{n}=8)$ versus the largest $(56 \%$ prevalence,

$279 \mathrm{n}=8$ ). Finally, a single OTU of Rickettsiella (Coxielliaceae) was only found in three C. belti individuals,

280 but was highly abundant ( $31 \%$ on average; Figure 3$)$. This OTU43304 was $99 \%$ similar to Rickettsiella

281 bacteria, also found in sand flies and ticks.

282

Bacteria associated with the eggs of Cephaloleia beetles found on native plants. Similar to the adults,

283 Cephaloleia eggs were examined for microbiome composition via 16S rRNA gene barcode sequencing

284 (Table 1). Four of the most common bacterial OTUs associated with adult beetles (Acinetobacter,

285 Enterobacteriaceae, Comamonas, and Pseudomonas) were consistently observed in eggs (Figure 7, Table

286 1), suggesting vertical transmission from mother to offspring. NMDS analysis revealed a general overlap

287 of the microbial communities associated with eggs and adults (ANOSIM R =0.19, p =0.060; Figure 6B).

288 The egg-associated microbiome of the generalist $C$. belti was significantly different from the adults

289 (ANOSIM R $=0.95, \mathrm{p}=0.022$ ), based mainly on a near absence of Rickettsia in the eggs (only $0.01 \%$

290 abundance; Figure 7, Table 1).

291 Cephaloleia beetles foraging on invasive plants have distinct microbiomes. Specialist Cephaloleia

292 species collected on invasive plants exhibited an apparent dysbiosis in their microbiome. NMDS

293

294

295

296

297

298 ordination revealed a distinct bacterial community structure between the specialist beetles collected from native plants, compared to those on invasive plants, including C. placida and C. dilaticollis both on white ginger (Hedychium coronarium; ANOSIM R $=0.97, \mathrm{p}=0.001$; Figure $6 \mathrm{C}$ ). The specialist species found on invasive plants possessed a lower abundance of both Moraxellaceae (21\% average 16S rRNA abundance when on invasive plants compared to $41 \%$ for native feeders; $\mathrm{P}=0.0472$, one-way ANOVA) and Enterobacteriaceae (6\% average abundance in beetles feeding on invasive plants, as opposed to 18\% for those feeding on native plants; $\mathrm{P}=0.0357$; Figure 2; Supplemental Table $\mathrm{S} 1$ ). This decrease in typical

300

301 microbiome membership may relate directly to a concomitant increase in microbiome members such as Brevinemataceae, which was significantly more abundant in both specialist species on invasive plants ( $21 \%$ average abundance; a single OTU43892, $99 \%$ similar to Brevinema found in insect larvae and other invertebrates, represented $97 \%$ of all Spirochaete sequences), compared to those on native plants $(2 \% ; \mathrm{P}=0.012$; Figure 2). The four specimens of the generalist species $C$. belti collected on pink banana 
305 (Musa velutina) also showed a slight shift in microbiome (ANOSIM $\mathrm{R}=0.27, \mathrm{p}=0.05$; Figure 6B;

306 Supplemental Table S1), with significant increases in Spiroplasmataceae and Enterobacteriaceae

307 abundance (ANOVA $\mathrm{p}=0.05$ for both; Figure 2).

308

\section{DISCUSSION}

310 Virtually every living organism has an associated collection of bacteria and bacteria-sourced genes (i.e.

311 microbiome), which account for more genetic and functional potential than even the host genome. Insects

312 have emerged to be important for this research due to their variable nutritional strategies and ecological

313 dominance. The speciose genus Cephaloleia has evolved in association with tropical ginger plants and,

314 for many species at La Selva Biological Station in northeastern Costa Rica, their specific host plant

315 associations are known. Several Cephaloleia species are also currently expanding their diets to include

316 exotic invasive plants, yet it is not known whether their microbial community plays a role in this

317 transition. For this reason, Costa Rican rolled-leaf beetles within the genus Cephaloleia present a unique

318 opportunity to distinguish the effects of host diet from host taxonomy on the associated gut bacteria, as

319

320

321

322

323

324

325

326

327 well as to explore whether movement of these specialized insects onto invasive host plants results in changes to the bacterial communities. The factors that affect insect gut bacterial communities are still not fully understood. In particular, diet has been shown to affect gut microbial communities in some insects (16) and conversely be a poor predictor of gut bacterial community composition in others (17). In this study, we show that the core microbiome of six closely related Cephaloleia species primarily includes the Moraxellaceae, Enterobacteriaceae, and Pseudomonadaceae, and that diet breadth is significantly linked to microbiome diversity and community structure.

Results suggest that the core recovered bacterial OTUs are may be beneficial to Cephaloleia beetle hosts. For example, four of the most common bacterial OTUs associated with adult beetles were consistently observed in eggs, suggesting vertical transmission from mother to offspring. Sampling occurred over the

329

330 course of 13 months, thus showing that these microbiome members likely have a non-transient relationship with their host. Additionally, Pseudomonas, Enterobacter, and Pantoea (also Enterobacteriaceae) have been found to play influential roles in development, nutrition, and success in other herbivorous beetles and true bugs (4,32; among others). A study by Minard et al. suggests that the mosquito Aedes albopictus specifically associates with Acinetobacter to help with digestion of plant nectar (33), while Acinetobacter and Pseudomonas in bark beetle digestive systems contribute to the nutritional requirements of the insect via the breakdown of plant-based compounds (34-35). Representative isolates within the Enterobacteriaceae and Moraxellaceae revealed distinct in vitro metabolic capabilities with regard to the break down plant-related compounds (ex. xylose, mannitol, and pectin) versus lipids, respectively. Previously, Enterobacteriaceae were also found in Bombyx mori larvae (Lepidoptera) to similarly utilize mannitol and pectin, suggesting a role in the digestion of the mulberry leaf diet of the host (36). Some Chrysomelid beetles can degrade pectin and cellulose on their own, without the need of symbionts (37-38), however, others lack this ability and, instead, possesses a highly specialized symbiont that degrades pectin (39). For the 4 species in this study, either situation may be possible. Additionally, many plants produce chemical toxins to defend against herbivory, and it is expected, although not well demonstrated, that bacterial symbionts could aid in detoxification of these defensive compounds (35). The primary food source of Cephaloleia beetles, the plant genus Heliconia, is known to produce polyphenolic compounds known as tannins (40). Interestingly, esterases in insects

347 have also been shown to detoxify defensive plant compounds (41), thus esterase-producing bacteria like 
348

349

350

351

352

353

354

355

356

357

358

359

360

361

362

363

364

365

366

367

368

369

370

371

372

373

374

375

376

377

378

379

380

381

382

383

384

385

386

387

388

389

390

391

Acinetobacter and Pseudomonas (39) could also provide this service to Cephaloleia. Preliminary experiments suggest that Acinetobacter isolates grow better in the presence of Calathea (Zingiberales) extract as the only source of nutrients. Tolerance to, and metabolism of, plant extracts hints at a possible role of either detoxification or direct nutrient acquisition by the dominant Cephaloleia microbiome, although further research with cultured bacterial isolates is necessary to examine this more fully.

Cephaloleia beetles in this study exhibited contrasting dietary breadths; the two generalist species $C$. belti and $C$. reventazonica feed on 9-15 plants from many Zingiberales families, while the four specialist species, including C. dilaticollis, C. dorsalis, C. fenestrata and C. placida, each feed on only 1-2 plant species $(12,15)$. This comparison of six congeneric Cephaloleia species with varying diet breadth satisfies the recommendation of Jones et al. (17) to essentially remove taxonomy as a factor confounding the influence of diet on the gut microbiome. Overall, the microbiome of specialists was significantly higher in diversity than generalists, and was comparatively dominated by the Moraxellaceae, Enterobacteriaceae, and Pseudomonadaceae. The shift shown in Figure 6A perhaps suggests that part of Axis 1 could be due to intrinsic species differences (ex. C. belti and C. reventazonica, the generalist species, appear separated), but that axis 2 is likely driven by diet breadth (all specialists cluster tightly together). It is worth noting here that $C$. dilaticollis encompasses two cryptic species, with opposing diet breadths, and that the individuals in this study possessed a microbiome community shared with other specialists. Thus, it was possible to infer the limited diet breath of this particular $C$. dilaticollis sub-species, based solely on a distinctive microbiome structure and diversity. The specialist sub-species of $C$. dilaticollis was subsequently confirmed via insect COI sequencing, in consultation with Dr. Carlos Garcia-Robledo (University of Connecticut).

Generalist Cephaloleia beetles were, by contrast, colonized by bacteria traditionally thought of as pathogens, including Rickettsia and Rickettsiella, and the pattern of occurrence in these beetles (Figure 3, shown in green) is consistent with a pathogen-like relationship (42) in that they infect only a few individuals (and thus exhibit low prevalence), but when present, they achieve high numbers (and thus high abundance). Individuals that were colonized by these groups demonstrated a striking paucity of several of the most prevalent 'core' microbiome members observed in all other beetles, including Acinetobacter and Enterobacteriaceae (Figures 2, 5). Sakurai et al. 2005 similarly showed that Rickettsia presence in aphids reduced the population of the beneficial bacterial symbiont Buchnera to 50-60\% of its density in Rickettsia-free individuals. If these interloper microbial groups are detrimental, it would follow that beetles demonstrating dysbiosis would suffer fitness deficits, including weight loss and poor survival. Indirect observations support this assertion, in that the smallest $C$. belti individuals appeared to have a higher incidence of Rickettsia colonization (75\%, as compared with $37 \%$ for the largest individuals, $\mathrm{n}=8$ in both groups). In other studies, Rickettsia has had a positive effect on insects, including higher fecundity, faster development, and fungal resistance (43-45). Whether beneficial or pathogenic, it will be interesting to further examine the possible antagonistic relationships among members of the Cephaloleia microbiome.

Over the past several years, at least eight Cephaloleia species at La Selva Biological Station have been found foraging on invasive crêpe ginger, false bird-of-paradise, pink velvet banana, and white ginger (27). In this study, specialist Cephaloleia species collected on invasive plants exhibited an apparent dysbiosis in the membership of both core groups, the Moraxellaceae and Enterobacteriaceae, and non-core groups Brevinemataceae and Spiroplasmataceae It is not known if these differences represent a change along a 
392

393

394

395

396

397

398

399

400

401

402

403

404

405

406

407

408

409

410

411

412

413

414

415

416

417

418

419

420

421

422

423

424

425

426

427

428

429

430

continuum as beetles adapt to exotic plants, or whether the changes in microbiome facilitate movement onto new plants, or neither. Determining whether an elastic microbial repertoire can be a form of direct, and rapid, environmental adaptation by the host is a next critical step given that the colonization of invasive plants is an inevitable new reality for all generalist and specialist herbivores. A 2013 NSFsponsored report urged the scientific community to better understand phenotypic plasticity and sensitivity of animals to future changing environments (46), yet none of the statements considered animal-associated microbiomes, or the immense potential of this metabolic reservoir for maintaining function in the face of changing ecosystems.

Conclusion. The tremendous diversity of insect herbivores, particularly in tropical rainforests, is due in part to the relative specificity of their diets (47-48). In this study, Costa Rican beetle species within the genus Cephaloleia, with known diet breadths ranging from generalist (foraging on 9-15+ plants) to specialist (foraging on $<2$ plant species), were analyzed for their associated gut microbial community. The core microbiome of six closely-related species of Costa Rican Cephaloleia beetles was limited and mainly included members of the Acinetobacter, Enterobacteriacea, Pseudomonas, Lactococcus, and Comamonas. Contrary to expectations, the microbiome diversity was significantly higher in specialist species, compared to generalists, and was dominated by these core groups (as were the eggs). Generalist beetles had lower diversity, primarily due to the exclusive dominance of bacteria thought to be pathogens, including the Rickettsiaceae. Bacteria isolated from Cephaloleia digestive systems had distinct capabilities in both digestion of plant-based compounds, including xylose, mannitol, and pectin, and possible detoxification of plant compounds via lipases. Additionally, changes in abundance of rare plants may significantly influence the balance between nutritional specificity and dietary breadth of herbivores (49), and in this study, Cephaloleia specimens collected from exotic invasive plants revealed a dysbiosis of the microbiome. In ecological terms, it may be possible in the future to use only microbiome patterns to know whether the beetles are surviving in native or exotic environments. Additional experiments are necessary to fully determine whether microbiome differences observed in this study are the product of intrinsic differences among species or result from shifts to novel plant diets, and what are the implications of replacement of native plants by exotic plants on the survival of beetles. The possible relationship between gut bacteria and niche adaptation, however, remains an important and urgent research question as organisms respond to future altered landscapes.

\section{ACKNOWLEDGEMENTS}

The authors thank Dr. Erin Brinton and Natalie Gonzalez for assisting in sample collection while in Costa Rica, Dr. Gretchen North for providing the intellectual support to identify plants, Dr. Carlos GarciaRobledo for sharing his knowledge of Cephaloleia, and the members of the Occidental College Microbial Symbiosis Laboratory. 
431

432

433

434

435

436

437

438

439

440

441

442

443

444

445

446

447

448

449

450

451

452

453

454

455

456

457

458

459

460

461

462

463

464

465

466

467

468

469

\section{References}

1. Moran, N.A. \& Telang, A. Bacteriocyte-associated symbionts of insects. BioScience 48, 295-304. (1998).

2. Wernegreen, J.J. Genome evolution in bacterial endosymbionts of insects. Nat. Rev. Genet. 3, 850-861 (2002).

3. Douglas, A.E. The microbial dimension in insect nutritional ecology. Funct. Ecol. 23, 38-47 (2009).

4. Bistolas, K.S., Sakamoto R.I., Fernandes J.A. \& Goffredi S.K. Symbiont polyphyly, co-evolution, and necessity in pentatomid stinkbugs from Costa Rica. Front Microbiol. 5, 349 (2014).

5. Genta F.A., Dillon R.J., Terra W. \& Ferreira C. Potential role for gut microbiota in cell wall digestion and glucoside detoxification in Tenebrio molitor larvae. J Insect Physiol 52, 593-601 (2006).

6. Kuriwada, T., Hosokawa, T., Kumano, N., Shiromoto, K., Haraguchi, D. \& Fukatsu, T. Biological role of Nardonella endosymbiont in its weevil host. PloS ONE 5, e13101 (2010).

7. Hansen, A.K. \& Moran, N.A. The impact of microbial symbionts on host plant utilization by herbivorous insects. Molecular Ecology 23, 1473-1496 (2014).

8. Staines, C.L. The genus Cephaloleia (Coleoptera: Chrysomelidae) in Central America and the West Indies. Rev. Biol. Trop. Special Publication 3, 3-87 (1996).

9. Wilf, P., Labandeira, C.C., Staines, C.L., Windsor, D.M., Allen, A.L. \& Johnson, K.R. Timing the radiations of leaf beetles: hispines on gingers from latest Cretaceous to recent. Science 289, 291-294 (2000).

10. McKenna D.D. \& Farrell, B.D. Tropical forests are both evolutionary cradles and museums of leaf beetle diversity. Proc Natl Acad Sci USA 103, 1047-1051 (2006).

11. García-Robledo C. \& Staines C.L. Herbivory in gingers from latest Cretaceous to present: is the ichnogenus Cephaloleichnites (Hispinae, Coleoptera) a rolled-leaf beetle? J Paleontology 82, 10351037 (2008).

12. McKenna D.D. \& Farrell B.D. Molecular phylogenetics and evolution of host plant use in the neotropical rolled leaf 'hispine' beetle genus Cephaloleia (chevrolat) (Chrysomelidae: Cassidinae). Mol Phylogenet Evol. 37, 117-131 (2005).

13. Staines C.L. Hispines (Chrysomelidae: Cassidinae) of La Selva Biological Station, Costa Rica. In: Jolivet P, Santiago-Blay J, Schmitt M, editors. Research on Chrysomelidae 3. Zookeys 157, 45-65 (2011).

14. García-Robledo, C. \& Staines, C.L. Monograph: The genus Cephaloleia in the Americas (Coleoptera: Chrysomelidae: Cassidinae). Zookeys. 436, 1-355 (2014).

15. García-Robledo C., Erickson D.L., Staines C.L., Erwin T.L. \& Kress W.J. Tropical plant-herbivore networks: reconstructing species interactions using DNA barcodes. PLoS ONE. 8, e52967 (2013).

16. Colman D.R., Toolson E.C. \& Takacs-Vesbach C.D. Do diet and taxonomy influence insect gut bacterial communities? Mol Ecol. 21, 5124-5137 (2012).

17. Jones R.T., Sanchez L.G. \& Fierer N. A cross-taxon analysis of insect-associated bacterial diversity. PLOS ONE. 8, e61218 (2013). 
470

471

472

473

474

475

476

477

478

479

480

481

482

483

484

485

486

487

488

489

490

491

492

493

494

495

496

497

498

499

500

501

502

503

504

505

506

507

18. Rahman, N.A., D.H. Parks, D.L. Willner, A.L. Engelbrektson, S.K. Goffredi, F. Warnecke, R.H. Scheffrahn \& P. Hugenholtz. A molecular survey of Australian and North American termite genera indicates that co-evolution is the primary force shaping termite gut microbiomes. Microbiome 3, 5 (2015).

19. García-Robledo C. \& Horvitz, C.C. Experimental demography and the vital rates of generalist and specialist insect herbivores on native and novel host plants. J Anim Ecol. 80, 976-989 (2011).

20. Douglas, A.E. Microbial brokers of insect-plant interactions revisited. J. Chem. Ecol. 39, 952-961 (2013).

21. Engel, P. \& Moran, N. A. The gut microbiota of insects-diversity in structure and function. FEMS Microbiology Reviews, 37, 699-735 (2013).

22. Caporaso J.G., Lauber C.L., Walters W.A., Berg-lyons D., Lozupone C.A., Turnbaugh P.J., Pierer N. \& Knight R. Global patterns of $16 \mathrm{~S}$ rRNA diversity at a depth of millions of sequences per sample. Proc Natl Acad Sci USA. 108, 4516-4522 (2011).

23. Berry D., Ben Mahfoudh K., Wagner M. \& Loy A. Barcoded primers used in multiplex amplicon pyrosequencing bias amplification. Applied Environmental Microbiology. 77, 7846-7849 (2011).

24. Kennedy K., Hall M.W., Lynch M.D., Moreno-Hagelsieb G. \& Neufeld J.D. Evaluating bias of Illumina-based bacterial 16S rRNA gene profiles. Applied Environmental Microbiology 80, 57175722 (2014).

25. Caporaso, J.G., Kuczynski, J., Stombaugh, J., Bittinger, K., Bushman, F.D., Costello, E.K., Fierer, N., Pena, A.G., Goodrich, J.K., Gordon, J.I. and Huttley, G.A. QIIME allows analysis of high-throughput community sequencing data. Nature Methods 7, 335-336 (2010).

26. Clarke K.R. \& Warwick R.M. Change in marine communities, 2nd edn. PRIMER-E Ltd.. Plymouth (2001).

27. Schneider C.A., Rasband W.S. \& Eliceiri K. NIH image to imageJ: 25 years of image analysis. Nature Methods 9, 671-675 (2012).

28. Giulieri S., Jaton K., Cometta A., Trellu L.T. \& Greub G. Development of a duplex real-time PCR for the detection of Rickettsia spp. and typhus group rickettsia in clinical samples. FEMS Immunol Med Microbiol 64, 92-97 (2012).

29. Haselkorn, T. S., Markow, T. A. \& Moran, N. A. Multiple introductions of the Spiroplasma bacterial endosymbiont into Drosophila. Molecular Ecology 18, 1294-1305 (2009).

30. Lane D.J. 16S and 23S rRNA sequencing, p 115-148. In Stackenbrandt E., \& Goodfellow M. (ed), Nucleic acid techniques in bacterial systematics. John Wiley and Sons, New York, NY (1991).

31. Li K., Chen H., Jiang J., Li X., Xu J. \& Ma Y. Diversity of bacteriome associated with Phlebotomus chinensis (Diptera: Psychodidae) sand flies in two wild populations from China. Sci Rep. 6, 36406 (2016).

32. Wang J., Chung S.H., Peiffer M., Rosa C., Hoover K., Zeng R. \& Felton G.W. Herbivore oral secreted bacteria trigger distinct defense responses in preferred and non-preferred host plants. $J$ Chem Ecol. 6, 463-474 (2016). 
508

509

510

511

512

513

514

515

516

517

518

519

520

521

522

523

524

525

526

527

528

529

530

531

532

533

534

535

536

537

538

539

540

541

542

543

544

545

546

547

33. Minard G., Tran F.H., Raharimalala F.N., Hellard E., Ravelonandro P., Mavingui P. \& Moro C.V. Prevalence, genomic and metabolic profiles of Acinetobacter and Asaia associated with field-caught Aedes albopictus from Madagascar. FEMS Microbiol Ecol. 83, 63-73 (2013).

34. Briones-Roblero C.I., Rodriguez-Diaz R., Santiago-Cruz J.A., Zuniga G. \& Rivera-Orduna F.N. Degradation capacities of bacteria and yeasts isolated from the gut of Dendroctonus rhyzophagus (Curculionidae: Scolytinae). Folia Micobiol. 62, 1-9 (2017).

35. Ceja-Navarro, J.A., Vega, F.E., Karaoz, U., Hao, Z., Jenkins, S., Lim, H.C., Kosina, P., Infante, F., Northen, T.R. \& Brodie, E.L. Gut microbiota mediate caffeine detoxification in the primary insect pest of coffee. Nature Communications, 6, 7618 (2015).

36. Anand A.A., Vennison S.J., Sankar S.G., Prabhu D.I., Vasan P.T., Raghuraman T., Geoffrey C.J. \& Vendan S.E. Isolation and characterization of bacteria from the gut of Bombyx mori that degrade cellulose, xylan, pectin and starch and their impact on digestion. J Insect Sci. 10, 107 (2010).

37. Pauchet, Y., Wilkinson, P. \& Chauhan, R. Diversity of beetle genes encoding novel plant cell wall degrading enzymes. PloS ONE, 5, e15635 (2010).

38. Busch, A., Kunert, G., Heckel, D.G. and Pauchet, Y. Evolution and functional characterization of CAZymes belonging to subfamily 10 of glycoside hydrolase family 5 (GH5_10) in two species of phytophagous beetles. PloS ONE, 12, e0184305 (2017).

39. Salem, H., Bauer, E., Kirsch, R., Berasategui, A., Cripps, M., Weiss, B., Koga, R., Fukumori, K., Vogel, H., Fukatsu, T. and Kaltenpoth, M. Drastic Genome Reduction in an Herbivore's Pectinolytic Symbiont. Cell, 171, 1520-1531 (2017).

40. Gibbs, R.D., 1974. Chemotaxonomy of flowering plants. Vols I-IV. McGill-Queen's univ. Press: Montreal \& London, 1, pp.1-680.

41. Snyder M.J., Champagne D.E., Cohen M.B. \& Howard J.J. Effects of plant diet on detoxification enzyme activities of two grasshoppers, Melanoplus differentialis and Taenipoda eques. J Chem Ecol. 24, 2151-2165 (1998).

42. Azad A.F. \& Beard C. Rickettsial pathogens and their arthropod vectors. Emerg Infect Dis. 4, 179186 (1998).

43. Sakurai M., Koga R., Tsuchida T., Meng X.Y. \& Fukatsu T. Rickettsia symbiont in the pea aphid Acrythosiphon pisum: novel cellular tropism, effect on host fitness, and interaction with the essential symbiont Buchnera. Appl Environ Microbiol. 71, 4069-4075 (2005).

44. Himler A.G., Adachi-Hagimori T., Bergen J.E., Kozuch A., Kelly S.E., Tabashnik B.E., Chiel E., Duckworth V.E., Dennehy T.J., Zchori-Fein E. \& Hunter M.S. Rapid spread of a bacterial symbiont in an invasive whitefly is driven by fitness benefits and female bias. Science. 332, 254-256 (2011).

45. Łukasik P., van Asch M., Guo H., Ferrari J. \& Godfray H.C.J. Unrelated facultative endosymbionts protect aphids against a fungal pathogen. Ecol. Lett. 16, 214-218 (2013).

46. Padilla, D.K., Daniel, T.L., Dickinson, P.S., Grünbaum, D., Hayashi, C., Manahan, D.T., Marden, J.H., Swalla, B.J. and Tsukimura, B. Addressing grand challenges In organismal biology: the need for synthesis. BioScience 64, 1178-1187 (2014).

47. Novotny, V., Drozd, P., Miller, S.E., Kulfan, M., Janda, M., Basset, Y. and Weiblen, G.D. Why are there so many species of herbivorous insects in tropical rainforests? Science 313,1115-1118 (2006). 
548 48. Forister, M.L., Novotny, V., Panorska, A.K., Baje, L., Basset, Y., Butterill, P.T., Cizek, L., Coley, 549 P.D., Dem, F., Diniz, I.R. and Drozd, P. The global distribution of diet breadth in insect herbivores. $550 \quad$ Proc Natl Acad Sci USA. 112, 442-447 (2015).

551 49. Norton, D. A. \& Didham, R. K. Comment on "Why are there so many species of herbivorous insects in tropical rainforests?". Science 315, 1666-1666 (2007). 
553

554

555

556

557

558

559

560

561

562

563

564

565

566

567

568

569

570

571

572

573

574

575

576

577

578

579

580

581

582

583

584

585

586

587

588

589

590

591

592

593

594

\section{Figure Legends}

Figure 1. Costa Rican Cephaloleia species in this study include (A) C. dilaticollis, (B) C. placida, (C) C. reventazonica, (D) C. dorsalis, (E) C. fenestrata, and (F) C. belti. (G) A mating pair of C. erichsonii on a young rolled leaf of Calathea lutea. All life stages and most behavior, including mating, take place on plants within the order Zingiberales. Scale bars $=1 \mathrm{~mm}$ for all images, except far right where the scale bar is $1 \mathrm{~cm}$. Photo credits: S. Goffredi

Figure 2. Relative abundance of bacterial families from (A) beetles foraging on native plants, including Cephaloleia placida, C. dilaticollis, C. fenestrata, C. doralis, C. belti, and C. reventazonica, and (B) beetles foraging on invasive plants $C$. placida, C. dilaticollis, and C. belti compared to those species foraging on native plants. Each color group on the graph represents a distinct genus-level OTU or lowest level available. Families that constituted $<1 \%$ of sequences from individual specimens were grouped as 'Other'.

Figure 3. Prevalence versus relative abundance of bacterial OTUs associated with 6 Cephaloleia species ( $\mathrm{n}=29$ specimens, collected on native diets). Certain dominant OTU groups are indicated separately by color (ex. Acinetobacter), with twelve shown by OTU\# based on $\geq 60 \%$ prevalence or $\geq 10 \%$ relative abundance (including 4 noted in green that matched bacterial groups typically thought of as pathogens).

Figure 4. Metabolic capabilities of bacteria isolated from the digestive system of Cephaloleia beetles, including the ability to use lactose/glucose, pectin, xylose, and mannitol, as well as the presence of proteases, esterases and lipases. White shading and the number ' 1 ' indicate the ability to digest the specified compound. Dark grey shading and the number ' 0 ' indicate an inability to digest the specified compound. Light grey shading and the number ' 0.5 ' indicate a weak reaction. At left, a phylogenetic tree, based on $767 \mathrm{bp}$ 16S rRNA sequences, built with Tamura-Nei distance model and UPGMA method, of beetle digestive system isolates shown to the left. Scale bar, 0.1 divergence.

Figure 5. Box plots of beetle-associated average diversity (Shannon index) and relative percent abundance of 4 key bacterial families (identified by SIMPER to be responsible for up to $46 \%$ of the cumulative (dis)similarity among six Cephaloleia species examined in this study $(\mathrm{n}=29$ specimens, collected on native diets)). Any data points outside of the $25-75 \%$ range are identified by open symbols. Species abbreviations are as follows: $\mathrm{Cp}=C$. placida, $\mathrm{Cdil}=C$. dilaticollis, $\mathrm{Cf}=C$. fenestrata, $\mathrm{Cdor}=C$. dorsalis, $\mathrm{Cb}=$ C. belti, $\mathrm{Cr}=$ C. reventazonica.

Figure 6. Non-metric Multidimensional Scaling (NMDS) ordination of microbial communities associated with Cephaloleia beetles. Each point represents all 16S rRNA sequences recovered from a single specimen. Displayed data was square root transformed, which minimizes errors in the ordination due to PCR bias while also not sacrificing genuine differences between samples. Samples with similar microbial communities plot closer together. ANOSIM p values are shown. Lower stress values indicate better representation of the intersample (dis)similarities in two dimensions. (A) Ordination comparing 4 specialist species and 2 generalist species, the latter designated by triangles. $p=0.001$, suggesting a distinct difference between the two feeding strategies. (B) Ordination showing the eggs of three species (outlined), compared to adults. $\mathrm{p}=0.060$ for all samples, suggesting a similarity to the communities found in specialist adults. $\mathrm{p}=0.022$ for the generalist species $C$. belti eggs versus adults, suggesting a significant difference between the two. (C) Ordination comparing 3 species, found on both native (filled symbols) and invasive plant species (open symbols). $\mathrm{p}=0.001$ for the two specialist species combined; $\mathrm{p}$ $=0.05$ for $C$. belti, suggesting a significant difference in both cases. 
595 Figure 7. Relative abundance of the 6 most dominant bacterial genera, based on 16S rRNA sequences, 596 recovered from eggs (left) and adults (right) of three Cephaloleia species. Species abbreviations are as

597 follows ( $\mathrm{n}$ egg, $\mathrm{n}$ adult, respectively): $\mathrm{Cb}=C$. belti $(2,8) \mathrm{Cdil}=C$. dilaticollis $(2,3), \mathrm{Cdor}=C$. dorsalis 598 (1,3). Photo credits: S. Goffredi 


\section{Table $\mathbf{1}$ (on next page)}

Beetle specimens analyzed in this study

Specimens analyzed in this study, showing the \# of 16S rRNA sequences generated from barcoding, along with corresponding measures of diversity. 
1 Table 1: Adult beetle specimens analyzed in this study, showing the \# of 16S rRNA sequences generated 2 from barcoding, along with corresponding measures of diversity.

\begin{tabular}{|c|c|c|c|c|c|}
\hline Species & Plant Diet $^{\text {a }}$ & Sample ID & $\begin{array}{c}\text { 16S rRNA } \\
\text { sequences } \\
\text { (initial \#) }\end{array}$ & $\begin{array}{c}\text { 16S rRNA } \\
\text { sequences } \\
\text { (normalized) }^{b}\end{array}$ & $\begin{array}{c}\text { Shannon } \\
\text { Diversity } \\
\text { Value }^{\mathrm{c}}\end{array}$ \\
\hline \multicolumn{6}{|c|}{ NATIVE PLANTS } \\
\hline \multirow[t]{8}{*}{ C. belti } & H. latisplatha & $\mathrm{Cb} 1$ & 35380 & 12958 & 2.50 \\
\hline & H. latisplatha & $\mathrm{Cb} 2$ & 41041 & 13039 & 2.29 \\
\hline & H. latisplatha & $\mathrm{Cb} 3$ & 40375 & 12939 & 2.14 \\
\hline & H. wagneriana & $\mathrm{Cb} 4$ & 35682 & 13276 & 1.80 \\
\hline & Calathea sp. & $\mathrm{Cb} 5$ & 23717 & 13158 & 1.73 \\
\hline & H. latisplatha & Cb6 & 21909 & 13186 & 0.82 \\
\hline & unknown & $\mathrm{Cb} 7$ & 43649 & 13018 & 1.94 \\
\hline & H. latisplatha & $\mathrm{Cb} 8$ & 20413 & 12959 & 2.26 \\
\hline \multirow[t]{3}{*}{ C. reventazonica } & H. imbracata & $\mathrm{Cr} 1$ & 20451 & 13177 & 1.89 \\
\hline & H. imbracata & $\mathrm{Cr} 2$ & 42274 & 13237 & 1.16 \\
\hline & H. imbracata & $\mathrm{Cr} 3$ & 32029 & 13324 & 1.81 \\
\hline \multirow[t]{7}{*}{ C. fenestrata } & Calathea sp. & Cf1 & 67826 & 12572 & 3.00 \\
\hline & Calathea sp. & Cf2 & 49366 & 12887 & 3.12 \\
\hline & Calathea sp. & Cf3 & 15568 & 13151 & 2.21 \\
\hline & Calathea sp. & Cf4 & 26983 & 12894 & 2.29 \\
\hline & Calathea sp. & Cf5 & 32891 & 12758 & 2.46 \\
\hline & H. imbracata & Cf6 & 31801 & 12637 & 2.11 \\
\hline & H. imbracata & Cf7 & 48964 & 12969 & 3.29 \\
\hline \multirow[t]{3}{*}{ C. dorsalis } & Co. malortiensus & Cdor1 & 41144 & 12755 & 2.97 \\
\hline & Co. malortiensus & Cdor2 & 54265 & 9899 & 2.91 \\
\hline & Co. malortiensus & Cdor3 & 51930 & 12711 & 2.05 \\
\hline \multirow[t]{3}{*}{ C. dilaticollis } & R. alpinia & Cdill & 45418 & 13084 & 2.38 \\
\hline & R. alpinia & Cdil2 & 47713 & 13096 & 2.47 \\
\hline & unknown & Cdil3 & 46765 & 12948 & 2.92 \\
\hline \multirow[t]{3}{*}{ C. placida } & R. alpinia & Cp1 & 40199 & 12979 & 2.79 \\
\hline & $R$. alpinia & Cp2 & 45794 & 11664 & 1.49 \\
\hline & $R$. alpinia & Cp3 & 41131 & 12782 & 2.16 \\
\hline
\end{tabular}




\begin{tabular}{|c|c|c|c|c|c|}
\hline & R. alpinia & Cp4 & 48511 & 13158 & 2.52 \\
\hline & R. alpinia & Cp5 & 37048 & 12770 & 3.08 \\
\hline \multicolumn{6}{|c|}{ INVASIVE PLANTS } \\
\hline \multirow[t]{4}{*}{ C. belti } & M. velutina & $\mathrm{Cb}$ inv 1 & 49334 & 13005 & 2.08 \\
\hline & M. velutina & $\mathrm{Cb}$ inv2 & 33427 & 13238 & 1.66 \\
\hline & M. velutina & $\mathrm{Cb}$ inv3 & 26965 & 12479 & 1.97 \\
\hline & M. velutina & $\mathrm{Cb}$ inv4 & 30173 & 12983 & 2.19 \\
\hline \multirow[t]{3}{*}{ C. dilaticollis } & He. coronarium & Cdil_inv1 & 15895 & 12268 & 2.32 \\
\hline & H. coronarium & Cdil_inv2 & 15679 & 12650 & 2.27 \\
\hline & H. coronarium & Cdil_inv3 & 23419 & 12473 & 3.02 \\
\hline \multirow[t]{2}{*}{ C. placida } & H. coronarium & Cp_inv1 & 13829 & 13128 & 2.39 \\
\hline & H. coronarium & Cp_inv2 & 26564 & 12733 & 3.15 \\
\hline \multicolumn{6}{|l|}{$E G G S$} \\
\hline \multirow[t]{2}{*}{ C. belti } & $n / a$ & $\mathrm{Cb}$ _egg1 & 68837 & 4410 & 2.90 \\
\hline & $n / a$ & Cb_egg2 & 55636 & 9715 & 3.36 \\
\hline C. dorsalis & $n / a$ & Cdor_egg1 & 45536 & 13217 & 2.84 \\
\hline \multirow[t]{2}{*}{ C. dilaticollis } & $n / a$ & Cdil_egg1 & 35848 & 6931 & 2.88 \\
\hline & $n / a$ & Cdil_egg2 & 18648 & 7305 & 3.55 \\
\hline
\end{tabular}

$4{ }^{\mathrm{a}} \mathrm{H} .=$ Heliconia,$H e .=$ Hedychium, $M .=$ Musa, $R .=$ Renealmia, Co. $=$ Costas

5 bdefine 'normalized' - without mitochondria and chloroplasts; with Wolbachia

6 cdiversity values without Wolbachia 


\section{Figure 1}

Costa Rican Cephaloleia species in this study

Costa Rican Cephaloleia species in this study include (A) C. dilaticollis, (B) C. placida, (C) C. reventazonica, (D) C. dorsalis, (E) C. fenestrata, and (F) C. belti. (G) A mating pair of $C$. erichsonii on a young rolled leaf of Calathea lutea. All life stages and most behavior, including mating, take place on plants within the order Zingiberales. Scale bars $=1 \mathrm{~mm}$ for all images, except far right where the scale bar is $1 \mathrm{~cm}$. Photo credits: S. Goffredi.
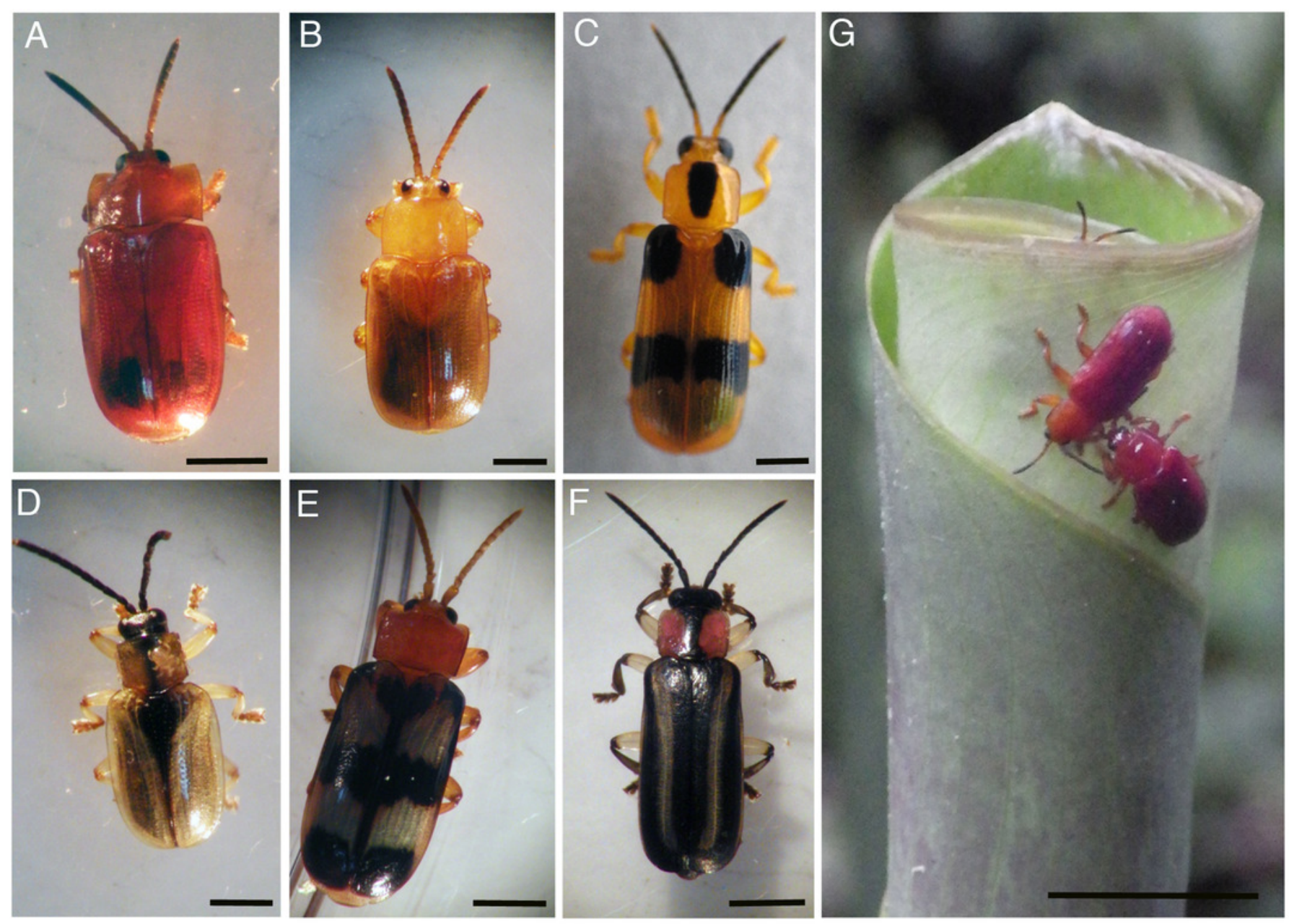


\section{Figure 2}

Relative abundance of bacterial families

Relative abundance of bacterial families from (A) beetles foraging on native plants, including Cephaloleia placida, C. dilaticollis, C. fenestrata, C. doralis, C. belti, and C. reventazonica, and (B) beetles foraging on invasive plants C. placida, C. dilaticollis, and C. belti compared to those species foraging on native plants. Each color group on the graph represents a distinct genus-level OTU or lowest level available. Families that constituted $<1 \%$ of sequences from individual specimens were grouped as 'Other'. 

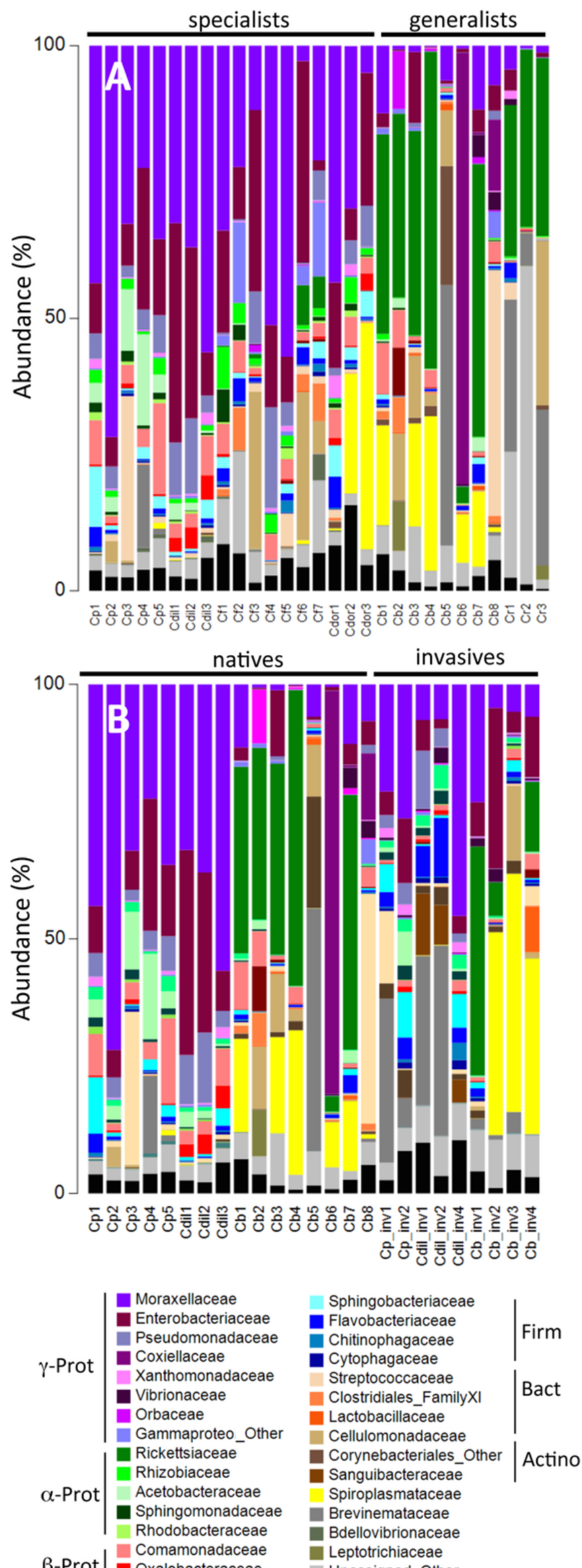

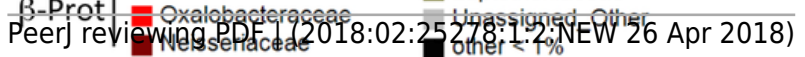


Figure 3

Prevalence versus relative abundance of bacterial OTUs

Prevalence versus relative abundance of bacterial OTUs associated with 6 Cephaloleia species ( $n=29$ specimens, collected on native diets). Certain dominant OTU groups are indicated separately by color (ex. Acinetobacter), with twelve shown by OTU\# based on $\geq$ $60 \%$ prevalence or $\geq 10 \%$ relative abundance (including 4 noted in green that matched bacterial groups typically thought of as pathogens).

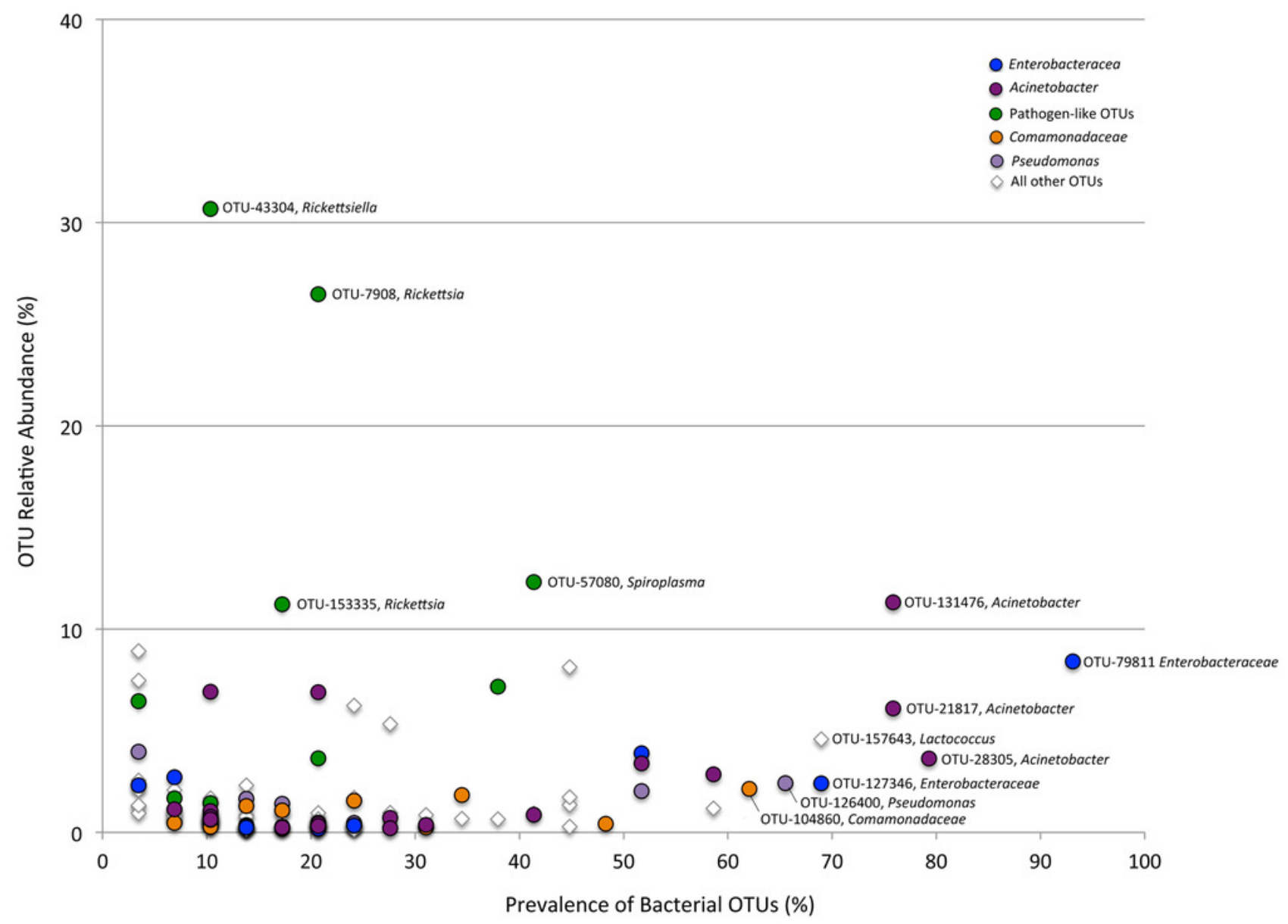




\section{Figure 4}

Metabolic capabilities of bacteria isolated from the digestive system of Cephaloleia beetles

Metabolic capabilities of bacteria isolated from the digestive system of Cephaloleia beetles, including the ability to use lactose/glucose, pectin, xylose, and mannitol, as well as the presence of proteases, esterases and lipases. White shading and the number ' 1 ' indicate the ability to digest the specified compound. Dark grey shading and the number ' 0 ' indicate an inability to digest the specified compound. At left, a phylogenetic tree, based on $767 \mathrm{bp} 16 \mathrm{~S}$ rRNA sequences, built with Tamura-Nei distance model and UPGMA method, of beetle digestive system isolates shown to the left. Scale bar, 0.1 divergence.

\begin{tabular}{|c|c|c|c|c|c|c|c|c|c|c|}
\hline & ID & Taxon & lact-/glucose & pectin & xylose & mannitol & protease & esterase $\mathrm{C}_{4}$ & lipase C8 & lipase $\mathrm{C} 14$ \\
\hline & Acineto1 & Acinetobacter & 0 & 0 & 0 & 0 & 1 & 1 & 1 & 1 \\
\hline & Acineto2 & Acinetobacter & 0 & 0 & 0 & 0 & 0 & 1 & 1 & 0 \\
\hline & Acineto3 & Acinetobacter & 0 & 0 & 0 & 0 & 0 & 1 & 1 & 1 \\
\hline & Acineto4 & Acinetobacter & 0 & 0 & 0 & 0 & 1 & 1 & 1 & 1 \\
\hline & Pseudo1 & Pseudomonas & 0 & 0 & 0 & 0 & 1 & 0 & 0 & 0 \\
\hline & Pseudo2 & Pseudomonas & 1 & 1 & 1 & 1 & 0 & 1 & 1 & 0 \\
\hline & Entero1 & Enterobacteraceae & 1 & 0.5 & 1 & 1 & 0 & 0 & 0 & 0 \\
\hline & Entero2 & Enterobacteraceae & 1 & 1 & 1 & 1 & 0 & 0 & 0 & 0 \\
\hline & Entero3 & Enterobacteraceae & 1 & 1 & 1 & 1 & 0 & 1 & 1 & 0 \\
\hline & Entero4 & Enterobacteraceae & 1 & 1 & 0.5 & 1 & 0 & 0 & 0 & 0 \\
\hline & Entero5 & Enterobacteraceae & 1 & 1 & 1 & 1 & 0 & 0 & 0 & 0 \\
\hline & Entero9 & Enterobacteraceae & 1 & 1 & 1 & 1 & 0 & 0 & 0 & 0 \\
\hline & Entero6 & Enterobacteraceae & 1 & 1 & 1 & 1 & 0 & 0 & 0 & 0 \\
\hline & Entero7 & Enterobacteraceae & 1 & 1 & 1 & 1 & 0 & 1 & 1 & 0 \\
\hline & Entero8 & Enterobacteraceae & 1 & 0 & 0 & 0.5 & 0 & 0 & 0 & 0 \\
\hline
\end{tabular}




\section{Figure 5}

Box plots of beetle-associated average diversity (Shannon index) and relative percent abundance of 4 key bacterial families

Box plots of beetle-associated average diversity (Shannon index) and relative percent abundance of 4 key bacterial families (identified by SIMPER to be responsible for up to $46 \%$ of the cumulative (dis)similarity among six Cephaloleia species examined in this study ( $\mathrm{n}=$ 29 specimens, collected on native diets)). Any data points outside of the $25-75 \%$ range are identified by open symbols. Species abbreviations are as follows: plac $=C$. placida, dilat $=C$. dilaticollis, fen $=C$. fenestrata, dor $=C$. dorsalis, belti $=C$. belti, rev $=C$. reventazonica. 


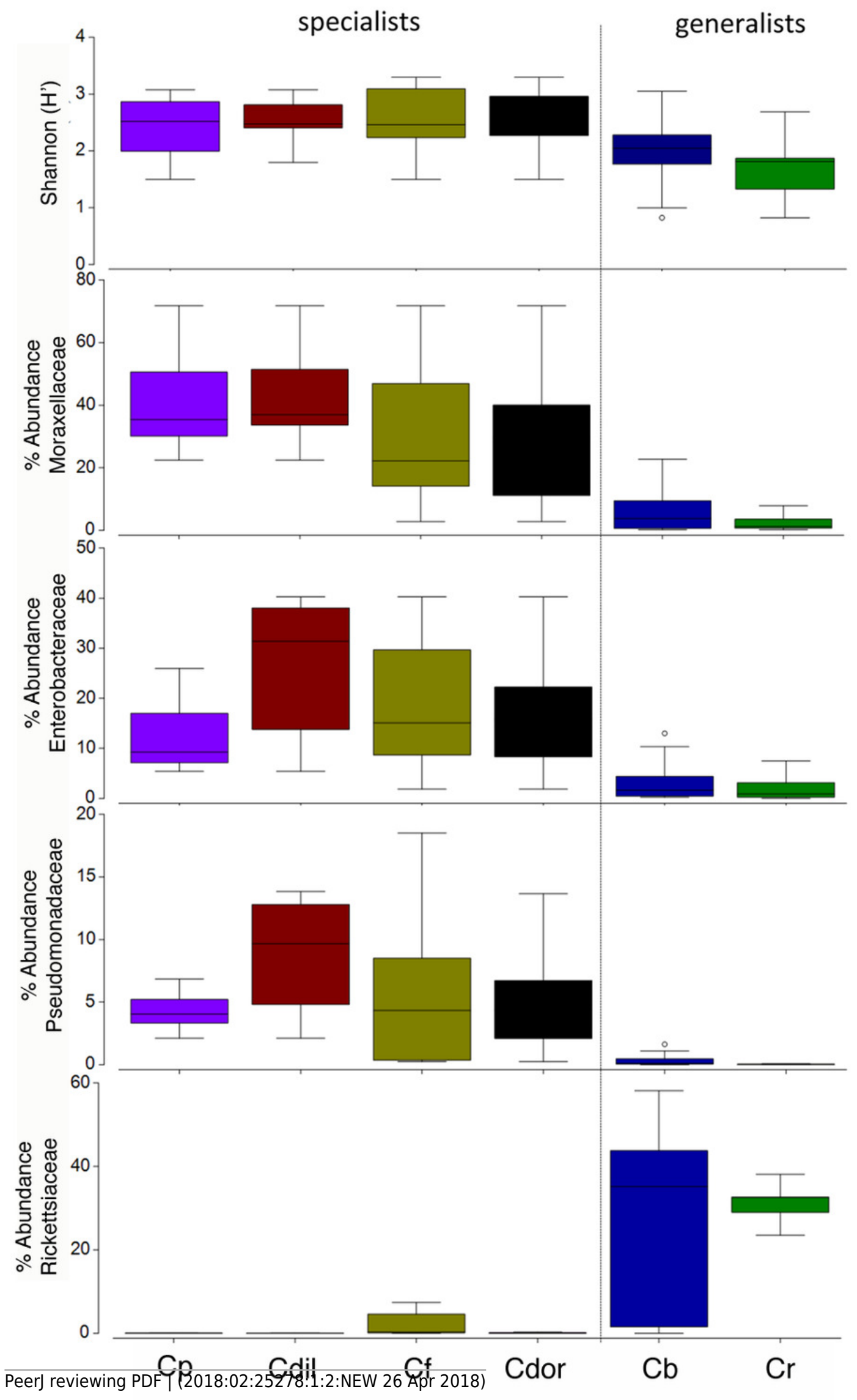




\section{Figure 6}

Non-metric Multidimensional Scaling (NMDS) ordination of microbial communities associated with Cephaloleia beetles

Each point represents all 16S rRNA sequences recovered from a single specimen. Displayed data was square root transformed, which minimizes errors in the ordination due to PCR bias while also not sacrificing genuine differences between samples. Samples with similar microbial communities plot closer together. ANOSIM $p$ values are shown. Lower stress values indicate better representation of the intersample (dis)similarities in two dimensions. (A) Ordination comparing 4 specialist species and 2 generalist species, the latter designated by triangles. $p=0.001$, suggesting a distinct difference between the two feeding strategies. (B) Ordination showing the eggs of three species (outlined), compared to adults. $p=0.060$ for all samples, suggesting a similarity to the communities found in specialist adults. $p=0.022$ for the generalist species $C$. belti eggs versus adults, suggesting a significant difference between the two. (C) Ordination comparing 3 species, found on both native (filled symbols) and invasive plant species (open symbols). $p=0.001$ for the two specialist species combined; $p$ $=0.05$ for $C$. belti, suggesting a significant difference in both cases. 


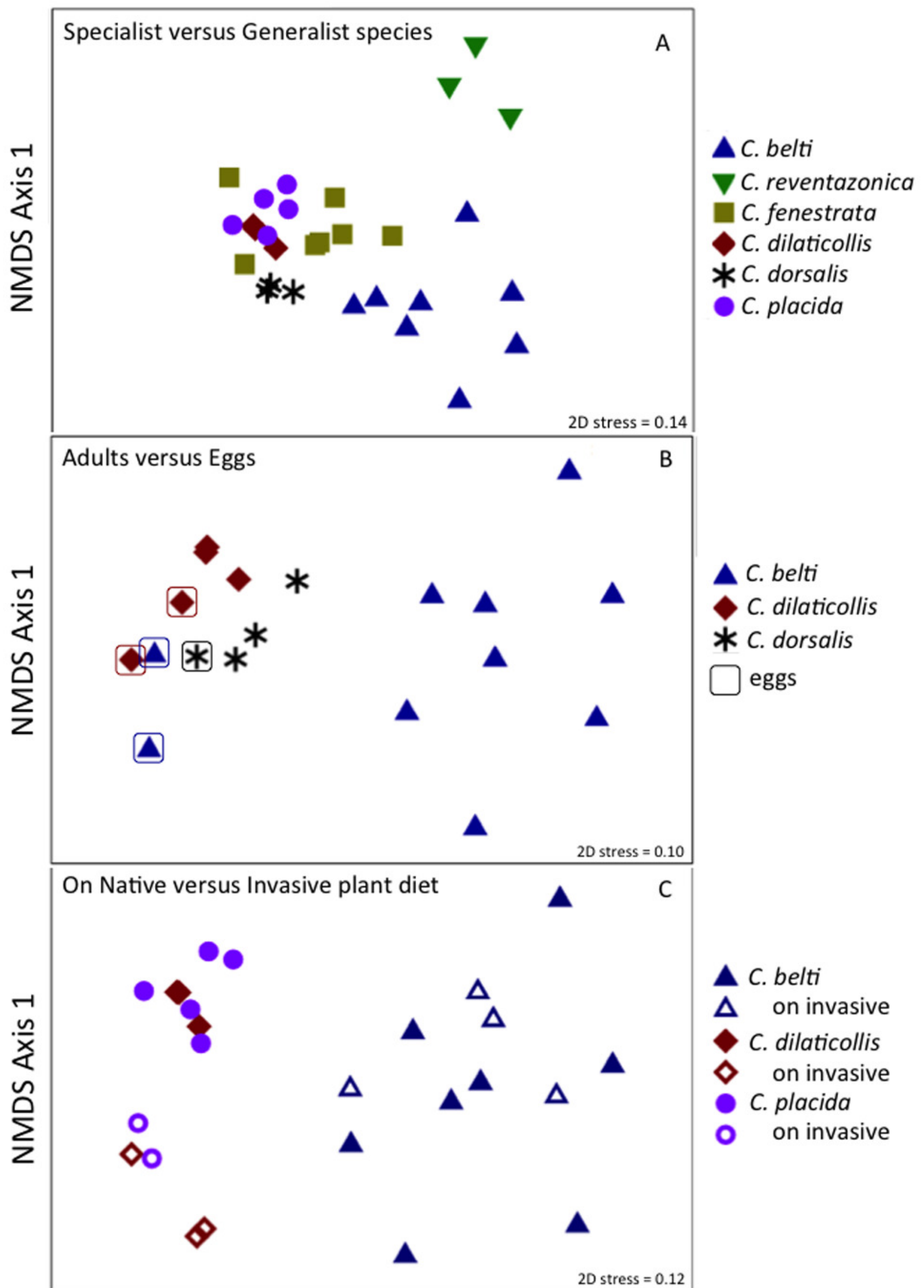




\section{Figure 7}

Dominant bacterial 16S rRNA sequences, recovered from eggs and adults of Cephaloleia species

Relative abundance of the 6 most dominant bacterial genera, based on 16S rRNA sequences, recovered from eggs (left) and adults (right) of three Cephaloleia species. Species abbreviations are as follows ( $\mathrm{n}$ egg, $\mathrm{n}$ adult, respectively): $\mathrm{Cb}=\mathrm{C}$. belti $(2,8) \mathrm{Cdil}=\mathrm{C}$. dilaticollis $(2,3)$, Cdor $=$ C. dorsalis $(1,3)$. Photo credits: S. Goffredi.

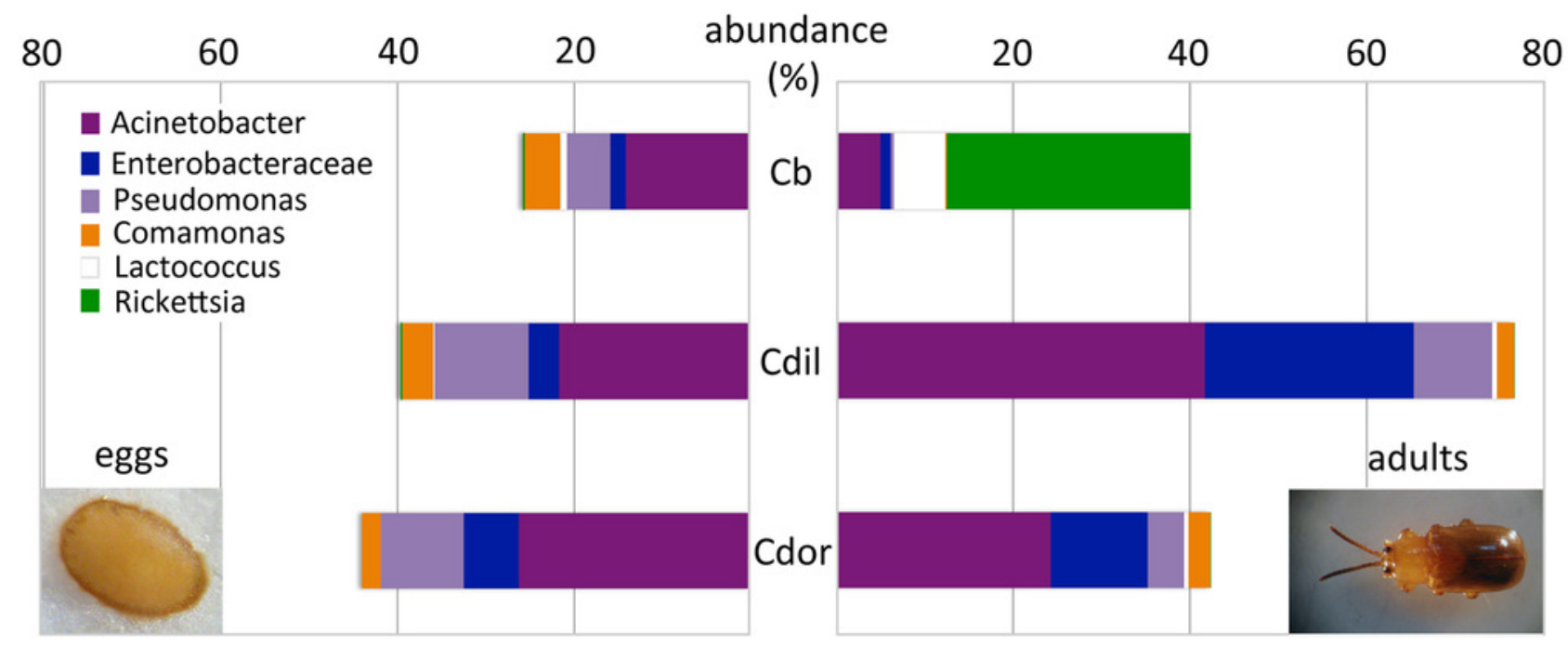

